\title{
World Journal of Venous thromboembolism in children Pediatric Surgery undergoing surgery: incidence, risk factors and related adverse events
}

\author{
Elbert Johann Mets, ${ }^{1}$ Ryan Patrick McLynn, ${ }^{1,2}$ Jonathan Newman Grauer (i) ${ }^{1}$
}

To cite: Mets EJ, McLynn RP, Grauer JN. Venous thromboembolism in children undergoing surgery: incidence, risk factors and related adverse events. World Jnl Ped Surgery 2020;3:e000084. doi:10.1136/ wjps-2019-000084

Received 30 August 2019 Revised 9 March 2020 Accepted 10 March 2020
Check for updates

(C) Author(s) (or their employer(s)) 2020. Re-use permitted under CC BY-NC. No commercial re-use. See rights and permissions. Published by BMJ.

${ }^{1}$ Department of Orthopaedics and Rehabilitation, Yale School of Medicine, New Haven, Connecticut, USA

${ }^{2}$ Department of Orthopaedic Surgery, University of Alabama at Birmingham, Birmingham, Alabama, USA

Correspondence to Dr Jonathan Newman Grauer; jonathan.grauer@yale.edu

\section{ABSTRACT}

Background Although less common in adults, venous thromboembolism (VTE) in children is a highly morbid, preventable adverse event. While VTE has been well studied among pediatric hospitalized and trauma patients, limited work has been done to examine postoperative VTE in children undergoing surgery.

Methods Using data from National Surgical Quality Improvement Project Pediatric database (NSQIP-P) from 2012 to 2016, a retrospective cohort analysis was performed to determine the incidence of, and risk factors for, VTE in children undergoing surgery. Additionally, the relationships between VTE and other postoperative adverse outcomes were evaluated.

Results 0 f 361384 pediatric surgical patients, 378 $(0.10 \%)$ were identified as experiencing postoperative VTE. After controlling for patient and surgical factors, we found that American Society of Anesthesiologists (ASA) class of II or greater, aged 16-18 years, non-elective surgery, general surgery (compared with several other surgical specialties), cardiothoracic surgery (compared with general surgery) and longer operative time were significantly associated with VTE in pediatric patients $(p<0.001$ for each comparison). Furthermore, a majority of adverse events were found to be associated with increased risk of subsequent VTE $(p<0.001)$.

Conclusion In a large pediatric surgical population, an incidence of postoperative VTE of $0.10 \%$ was observed. Defined patient and surgical factors, and perioperative adverse events were found to be associated with such VTE events.

\section{INTRODUCTION}

Venous thromboembolism (VTE) in children is a rare condition that includes deep vein thrombosis (DVT) and/or pulmonary embolism (PE). While there has been much written about VTE in the general hospitalized pediatric population (estimating an incidence between $0.18 \%$ and $0.58 \%$ of admissions), ${ }^{1-9}$ and in children after trauma (estimated incidence between $0.02 \%$ and $0.33 \%^{10}{ }^{11}$ ), there has been little investigation of VTE in children undergoing surgery. ${ }^{12-14}$

Several risk factors for VTE in children have been identified, including hematological malignancy (2.5-fold increased risk),
Key messages

What is already known about this subject?

- Previous studies have described the incidence of venous thromboembolism (VTE) in children undergoing surgery as between $0.04 \%$ and $8.9 \%$, depending on surgical specialty.

- Risk factors for VTE among pediatric surgical patients include: central venous lines, hematological malignancy, trauma/burns, prolonged ventilator use and longer hospital stay.

- Among children, neonates and adolescents are at greatest risk of developing VTE.

What are the new findings?

- Children undergoing surgery are at higher risk of VTE if they are aged 16-18 years, have worse overall health status by the American Society of Anesthesiologists (ASA) classification and undergo longer, non-elective surgeries.

- Patients experiencing any adverse event after surgery, including medical and surgical adverse events, reoperation and readmission, are at increased risk of subsequent VTE.

- Children undergoing general surgery and cardiothoracic surgery are at higher risk of VTE compared with other surgical specialties.

How might it impact on clinical practice in the foreseeable future?

- The current study adds to the limited literature characterizing risk factors for postoperative VTE among pediatric surgical patients.

- Weighing the risks and benefits of such an intervention, children identified to be at higher risk of VTE could potentially benefit from thromboprophylaxis when undergoing surgery.

orthopedic surgery (2.2-fold increased risk), ${ }^{7}$ severe or critical injury (2.5-fold to 43.5 -fold increased risk), ${ }^{11}$ prolonged ventilator use (1.3-fold increased risk $)^{19}$ and longer hospital length of stay (1.03-fold increased risk). ${ }^{18}$ Among children, VTE is most common in neonates and adolescents, with adolescents at highest risk. ${ }^{5-8} 1517-20$ Additionally, VTE occurs more commonly in tertiary care centers than in community hospitals. ${ }^{48}$ 
In a study looking at surgical populations, Humes et al evaluate VTE in children in the year after general surgery and found the overall incidence to be $0.44 \%$ and risk factors to include at least one significant comorbidity. ${ }^{14}$ Georgopoulos et al investigated VTE in children after elective pediatric orthopedic surgery and found the incidence to be $0.063 \%$ and risk factors to be older age, obesity and surgical complications. ${ }^{1}$

Additionally, Cairo et al and Ahn et al have recently identified risk factors for VTE among pediatric surgical patients, both using the National Surgical Quality Improvement Project Pediatric database (NSQIP-P). ${ }^{12} 13$ Both studies used large numbers of patients to define demographic factors that predisposed to VTE in children, but did not take into account the factors that occurred postoperatively.

Although it is rare, the occurrence of VTE can be associated with significant morbidity in children. Complications occurring most commonly after VTE include post-thrombotic syndrome (estimated incidence of $26 \%$ after DVT in one systematic review), ${ }^{21}{ }^{22}$ and increased risk of mortality (relative risk of 6.27 compared with patients without VTE, ${ }^{81}$ with mortality related to VTE estimated at 2.2\%). ${ }^{2}$ Furthermore, among pediatric patients treated after trauma, VTE has been linked to higher costs and longer hospital lengths of stay. ${ }^{1016}$

Nonetheless, due to the low incidence of VTE in the pediatric population undergoing surgical intervention, prophylaxis is generally not used as it is in the adult population. As with any prophylactic regimen, the risks and benefits of any such intervention are used to derive recommendations to optimize outcomes. At present, few specific guidelines exist regarding VTE prophylaxis in children undergoing surgery. ${ }^{18} 2324$

In the UK, the Association of Pediatric Anesthetists of Great Britain and Ireland (APAGBI) published guidelines for prevention of perioperative VTE in pediatric patients. ${ }^{24}$ The guidelines suggest that all pediatric surgical candidates aged 13 years and older should be evaluated for their risk of VTE. In addition to nonpharmacological prophylactic measures (early mobilization, reduction of risk factors), in 'higher risk' adolescents (those with more than two risk factors) expected to have significantly reduced mobility for $>48$ hours, chemoprophylaxis with low molecular weight heparin could be considered. However, the authors note the limited nature of the existing evidence on the topic.

Similarly, citing a paucity of evidence on the efficacy of prophylactic anticoagulation in pediatric patients, the present guidelines from the British Society of Haematology for pharmacological thromboprophylaxis in children suggest that "children, particularly adolescents, with multiple risk factors for VTE should be considered for thromboprophylaxis with (low molecular weight heparin) ${ }^{25}$ The guidelines advocate for additional studies to elucidate risk factors for VTE in the pediatric population.
Attesting to the efficacy of thromboprophylaxis guidelines for reducing the risk of VTE, especially in critically ill children after trauma, a single center's VTE prophylaxis clinical practice guideline for pediatric trauma patients at high risk of VTE has shown prophylaxis to be associated with reductions in the incidence of VTE from $5.2 \%$ to $1.8 \%$ with no bleeding complications. ${ }^{23}{ }^{26}$ These findings suggest that thromboprophylaxis for high-risk patients can safely be applied.

It is hypothesized that patients' demographic, operative variables as well as perioperative events may influence the rate of VTE in pediatric surgical populations. However, due to the low incidence of such occurrences, a large national dataset is required to make such assessments. If risk factors for VTE could be better identified and quantified in the postoperative setting, the risk/ benefit assessments for VTE prophylaxis could be better assessed in pediatric subpopulations.

\section{METHODS}

\section{Study design and patient population}

A retrospective cohort analysis was performed using data from the NSQIP-P database, aggregated from 2012 to 2016. This national database includes patients under 18 years of age undergoing surgery for non-traumatic indications (except for isolated limb section fractures) at multiple hospitals. The database included both inpatient and outpatient cases. Specifically trained nurses collected patient data perioperatively, and tracked patients for 30-postoperative days, regardless of discharge status.

All patients in the database from 2012 to 2016 with complete data were included in the analysis.

\section{Patient characteristics}

Patient demographic variables were abstracted directly from the database, including: age, sex and American Society of Anesthesiologists (ASA) classification. Patient comorbidities were also assessed. While ASA class was used as a marker of overall health, individual and grouped comorbidities were also abstracted from the database. A number of comorbidity groupings were aggregated from defined variables in the database. Pulmonary comorbidities included: history of ventilator dependence, asthma, bronchopulmonary dysplasia/chronic lung disease, oxygen support, tracheostomy and structural pulmonary or airway abnormalities. Cardiac disease included: history of cardiac surgery, inotrope support, recent cardiopulmonary resuscitation and cardiac risk factors (major or minor as defined in the database). Neurological disease included cerebral palsy, neuromuscular disorder, seizure disorder, history of intraventricular hemorrhage, structural central nervous system abnormality and impaired cognitive status. Data on esophageal/gastric/intestinal disease, hematological disease, steroid use within 30 preoperative days and preoperative blood transfusion were also abstracted from the database. 
Surgical variables and 30 -day outcomes

Data related to the operation performed were directly abstracted from the database. These included: operating surgeons' specialty and whether the operation was nonelective. Operative time in minutes, defined as the time from skin incision to closure, was directly abstracted from the database, as was length of stay in days (time from admission to discharge).

Thirty-day perioperative outcomes were directly abstracted from the database, and were classified into medical and surgical adverse events. Surgical adverse events were nerve injury, wound dehiscence (further subclassified as superficial or deep), flap failure, surgical site infection (SSI; superficial, deep or organ/space), and bleeding requiring transfusion. Medical adverse events were reintubation, renal failure and insufficiency, seizure, pneumonia, Clostridium difficile colitis, cardiac arrest, stroke, sepsis, septic shock, central line-associated bloodstream infection (CLABSI), urinary tract infection (UTI), coma and death. Any adverse event was noted when a patient experienced a medical or surgical adverse event.

Data on unplanned reoperation and readmission were also abstracted from the database. These were not categorized as medical or surgical adverse events but contributed to the total number of adverse events.

Patients were noted to have VTE if they experienced a DVT or PE. In calculating the cumulative incidence of adverse events, VTE contributed to the total number of adverse events (ie, 'any adverse event') and the number of medical adverse events. NSQIP-P includes variables which note the postoperative day on which adverse events occur. These variables were used to determine whether any of the perioperative adverse outcomes occurred before VTE.

\section{Statistical analysis}

Chi-squared tests were used to compare categorical preoperative and intraoperative variables between patients who did and did not experience a postoperative VTE. These variables included comorbidities, categorical demographic variables (sex and ASA class), surgeons' specialty and whether a surgery was non-elective. Comparisons of continuous perioperative variables (operative time, length of stay) between patients who did and did not develop VTE, were performed using two-tailed t-tests after assessing for equality of variances using Levene's test.

Multivariable logistic regression analyses were performed. One logistic regression was used to determine the odds ratios (ORs) for VTE, for all demographic and operative variables. To reduce collinearity in the model, rather than including comorbidities, ASA class was included to represent patients' overall health status.

After controlling for patient age, sex and ASA class (ie, these variables were included as predictor variables in each model), a second set of 26 Firth logistic regressions was performed to determine the ORs of VTE, for
non-VTE adverse events that occurred before a VTE. Firth logistic regressions were used for these analyses, as this method is better suited to determining the odds of rare events than traditional multivariate regressions. ${ }^{27}$

Bonferroni corrections for multiple comparisons were performed for each group of univariate analyses. Statistical analysis was performed using Stata V.16.0 (StataCorp, College Station, Texas, USA).

\section{RESULTS}

\section{Patient characteristics}

In total, 361384 patients were identified in the NSQIP-P database from 2012 to 2016 and included in the study after excluding patients with missing values. Patients' mean \pm SD age was $7.39 \pm 5.69$ years (range $0-18$ years), with $56.89 \%$ being male and $43.19 \%$ being female (table 1 ).

Regarding comorbidities, $24.54 \%$ of patients had an ASA class of III or greater (tables 1 and 2). The rates of individual and grouped comorbidities are given in table 2. The most common comorbidities in the dataset included neurological disease (23.82\%), esophageal/ gastric/intestinal disease $(16.95 \%)$, pulmonary disease $(14.80 \%)$ and cardiac disease $(9.76 \%)$.

Of this population, 378 patients $(0.10 \%)$ experienced a VTE within 30 postoperative days. Compared with patients without VTE, patients with VTE had a distribution of ages that included more older and younger patients $(p<0.001)$. However, groups were no different for sex $(p=0.414)$. Patients who developed VTE had a significantly higher overall ASA class and all seven types of comorbidities examined (table 2, $\mathrm{p}<0.001$ for all significant comparisons). Comorbidities most commonly seen among patients with VTE include esophageal/gastric/ intestinal disease $(46.30 \%)$, pulmonary disease $(45.50 \%)$ and neurological disease $(44.44 \%)$.

\section{Surgical variables and perioperative outcomes}

From the overall cohort, general surgery was the most common treating specialty (137181 patients, 37.96\%), followed by orthopedic surgery $(69,605,19.26 \%)$ and otolaryngology (45 226, 12.51\%; table 3). About a quarter of surgeries $(26.65 \%)$ were non-elective, with patients who went on to have a VTE being more likely to undergo non-elective surgery $(p<0.001$; table 3$)$. Overall differences in surgeons' specialty (eg, general surgery vs orthopedic surgery) were noted between patients with and without VTE $(\mathrm{p}<0.001)$.

Continuous operative variables are given in table 4 . On average, operations lasted $95.57 \pm 93.27 \mathrm{~min}$, with patients remaining in the hospital $4.61 \pm 13.53$ days postoperatively. Patients with VTE had significantly longer operative times and lengths of hospital stay $(\mathrm{p}<0.001$ for both comparisons).

Temporally considering VTE relative to other postoperative adverse events, of the 378 patients who experienced a VTE, 221 (58.47\% of patients with VTE) experienced an adverse event prior to VTE. The incidences of adverse 
Table 1 Demographic information for patients with and without postoperative VTE

\begin{tabular}{|c|c|c|c|c|c|c|c|}
\hline \multirow[b]{3}{*}{ Variables } & \multicolumn{2}{|l|}{ Total } & \multicolumn{2}{|l|}{ No VTE } & \multicolumn{2}{|l|}{ VTE } & \multirow[b]{3}{*}{ P value* } \\
\hline & \multicolumn{2}{|c|}{$\mathrm{n}=361384$} & \multicolumn{2}{|c|}{$n=361006(99.90 \%)$} & \multicolumn{2}{|c|}{$n=378(0.10 \%)$} & \\
\hline & $\mathbf{n}$ & $\%$ & $\mathbf{n}$ & $\%$ & $\mathbf{n}$ & $\%$ & \\
\hline Age, years (mean $\pm S D)$ & $7.39 \pm 5.6$ & & $7.39 \pm 5.6$ & & 7.27 & & $<0.001$ \\
\hline$\leq 1$ & 71227 & 19.71 & 71107 & 19.70 & 120 & 31.75 & \\
\hline $2-5$ & 77789 & 21.53 & 77720 & 21.53 & 69 & 18.25 & \\
\hline $6-10$ & 81015 & 22.42 & 80980 & 22.43 & 35 & 9.26 & \\
\hline $11-15$ & 85333 & 23.61 & 85263 & 23.62 & 70 & 18.52 & \\
\hline $16-18$ & 46020 & 12.73 & 45936 & 12.72 & 84 & 22.22 & \\
\hline Sex & & & & & & & 0.414 \\
\hline Male & 205424 & 56.89 & 205217 & 56.85 & 207 & 54.76 & \\
\hline Female & 155960 & 43.19 & 155789 & 43.15 & 171 & 45.24 & \\
\hline ASA class & & & & & & & $<0.001$ \\
\hline 1 & 116379 & 32.23 & 116369 & 32.23 & 10 & 2.65 & \\
\hline II & 156319 & 43.29 & 156247 & 43.28 & 72 & 19.05 & \\
\hline III & 79763 & 22.09 & 79568 & 22.04 & 195 & 51.59 & \\
\hline IV & 8537 & 2.36 & 8446 & 2.34 & 91 & 24.07 & \\
\hline V & 386 & 0.11 & 376 & 0.10 & 10 & 2.65 & \\
\hline
\end{tabular}

${ }^{*} \chi^{2}$ test comparing patients with and without VTE. Bolding indicates statistical significance at $\mathrm{p}<0.017$ (Bonferroni correction).

ASA, American Society of Anesthesiologists; VTE, venous thromboembolism.

events in the overall study population, as well as adverse events preceding VTE, are given in table 5. Considering patients who experienced an adverse event prior to VTE, 139 (36.77\% of VTE) experienced a surgical adverse event, while $93(24.60 \%)$ experienced a medical adverse event. Of the surgical adverse events experienced prior to VTE, bleeding requiring transfusion (117 patients, $30.95 \%$ of VTE), and organ/space SSI (19 patients, 5.03\%) were most common. Of the medical adverse events experienced prior to VTE, unplanned reintubation was most common (40 patients, $10.58 \%$ ), followed by sepsis (25, $6.61 \%)$ and pneumonia $(20,5.29 \%)$. Furthermore, 57 patients $(15.08 \%)$ underwent reoperation prior to VTE, and $48(12.70 \%)$ were readmitted before VTE.

\section{Logistic regression analysis}

The first logistic regression analysis performed calculated the ORs of VTE for demographic and operative variables. Demographic variables significantly associated with VTE included: age 16-18 years relative to 11-15 years (OR 1.892, 95\% confidence interval [CI] 1.374 to $2.606, \mathrm{p}<0.001$ ), age $6-10$ years (OR $0.625,95 \%$ CI 0.414 to $0.940, \mathrm{p}=0.024)$ and ASA class II or higher $(\mathrm{p}<0.001$ for each ASA class $>$ I). In the same model, operative variables

Table 2 Comorbidities of patients with and without postoperative VTE

\begin{tabular}{|c|c|c|c|c|c|c|c|}
\hline \multirow[b]{3}{*}{ Comorbidities } & \multirow{2}{*}{\multicolumn{2}{|c|}{$\begin{array}{l}\text { Total } \\
\mathrm{n}=361384\end{array}$}} & \multirow{2}{*}{\multicolumn{2}{|c|}{$\begin{array}{l}\text { No VTE } \\
n=361006(99.90 \%)\end{array}$}} & \multirow{2}{*}{\multicolumn{2}{|c|}{$\begin{array}{l}\text { VTE } \\
n=378(0.10 \%)\end{array}$}} & \multirow[b]{3}{*}{ P value } \\
\hline & & & & & & & \\
\hline & $\mathbf{n}$ & $\%$ & $\mathbf{n}$ & $\%$ & $\mathbf{n}$ & $\%$ & \\
\hline ASA class $\geq$ III & 88686 & 24.54 & 88390 & 2.45 & 296 & 78.31 & $<0.001$ \\
\hline Pulmonary disease & 53486 & 14.80 & 53314 & 1.48 & 172 & 45.50 & $<0.001$ \\
\hline Cardiac disease & 35282 & 9.76 & 25163 & 0.70 & 119 & 31.48 & $<0.001$ \\
\hline Esophageal/gastric/intestinal disease & 61259 & 16.95 & 61084 & 1.69 & 175 & 46.30 & $<0.001$ \\
\hline Neurological disease & 86080 & 23.82 & 85912 & 2.38 & 168 & 44.44 & $<0.001$ \\
\hline Hematological disease & 10984 & 3.04 & 10916 & 0.30 & 68 & 17.99 & $<0.001$ \\
\hline Preoperative steroids & 8319 & 2.30 & 8243 & 0.23 & 76 & 20.11 & $<0.001$ \\
\hline Preoperative transfusion & 2948 & 0.82 & 2902 & 0.08 & 46 & 12.17 & $<0.001$ \\
\hline
\end{tabular}

${ }^{*} \chi^{2}$ test comparing patients with and without VTE. Bolding indicates statistical significance at $p<0.006$ (Bonferroni correction for multiple corrections).

ASA, American Society of Anesthesiologists; VTE, venous thromboembolism. 
Table 3 Categorical perioperative factors in patients with and without postoperative VTE

\begin{tabular}{|c|c|c|c|c|c|c|c|}
\hline \multirow[b]{3}{*}{ Operative variable } & \multicolumn{2}{|l|}{ Total } & \multicolumn{2}{|l|}{ No VTE } & \multicolumn{2}{|l|}{ VTE } & \multirow[b]{3}{*}{ P value* } \\
\hline & \multicolumn{2}{|c|}{$\mathrm{n}=361384$} & \multicolumn{2}{|c|}{$\mathrm{n}=361006(99.90 \%)$} & \multicolumn{2}{|c|}{$\mathrm{n}=378(0.10 \%)$} & \\
\hline & $n$ & $\%$ & $n$ & $\%$ & $n$ & $\%$ & \\
\hline Surgical specialty & & & & & & & $<0.001$ \\
\hline Cardiothoracic surgery & 426 & 0.12 & 421 & 0.12 & 5 & 1.32 & \\
\hline Gynecology & 848 & 0.23 & 846 & 0.23 & 2 & 0.53 & \\
\hline General surgery & 137181 & 37.96 & 136950 & 37.94 & 231 & 61.11 & \\
\hline Neurosurgery & 34043 & 9.42 & 33983 & 9.41 & 60 & 15.87 & \\
\hline Orthopedic surgery & 69605 & 19.26 & 69557 & 19.27 & 48 & 12.70 & \\
\hline Otolaryngology (ENT) & 45226 & 12.51 & 45207 & 12.52 & 19 & 5.03 & \\
\hline Urology & 40800 & 11.29 & 40790 & 11.30 & 10 & 2.65 & \\
\hline Plastic surgery & 33255 & 9.20 & 33252 & 9.21 & 3 & 0.79 & \\
\hline Non-elective surgery & 96306 & 26.65 & 96162 & 26.64 & 144 & 38.10 & $<0.001$ \\
\hline
\end{tabular}

${ }^{*} \chi^{2}$ test comparing patients with and without VTE. Bolding indicates statistical significance at $\mathrm{p}<0.025$ (Bonferroni correction for multiple comparisons).

ENT, ear, nose and throat; VTE, venous thromboembolism.

significantly associated with higher risk of VTE were: non-elective surgery (OR 1.678, 95\% CI 1.332 to 2.114, $\mathrm{p}<0.001)$ and longer operative time in minutes (OR $1.004,95 \%$ CI 1.003 to $1.004, \mathrm{p}<0.001)$. Compared with general surgery, cardiothoracic surgery was associated with a higher likelihood of VTE (OR 3.248, 95\% CI 1.293 to $8.156, \mathrm{p}=0.012$ ). Furthermore, compared with general surgery, several surgical specialties were associated with lower odds of VTE. These were: neurosurgery (OR 0.622, $95 \%$ CI 0.463 to $0.837, \mathrm{p}=0.002$ ), orthopedic surgery (OR $0.496,95 \%$ CI 0.341 to $0.704, \mathrm{p}<0.001)$, otolaryngology (OR $0.465,95 \%$ CI 0.288 to 0.749 , $\mathrm{p}=0.002$ ), urology (OR $0.310,95 \%$ CI 0.162 to $0.594, \mathrm{p}<0.001)$ and plastic surgery (OR $0.141,95 \% 0.045$ to $0.443, \mathrm{p}=0.001$ ). ORs and $95 \%$ CIs for this model are given in table 6 .

After controlling for patient age, sex and ASA class, 26 Firth logistic regression analyses were performed to calculate the ORs of VTE for postoperative adverse events that occurred before a VTE. Of the adverse events examined, any adverse event (OR 13.275, 95\% CI 10.490 to $16.060, \mathrm{p}<0.001)$, surgical adverse events (OR 12.358, 95\% CI 9.559 to $15.156, \mathrm{p}<0.001)$, medical adverse events (OR $11.750,95 \%$ CI 8.957 to $14.543, \mathrm{p}<0.001$ ), reoperation (OR $11.479,95 \%$ CI 8.668 to $14.290, \mathrm{p}<0.001$ ) and readmission (OR 11.741, 95\% CI 8.931 to 14.551 , $\mathrm{p}<0.001)$ were all associated with higher risk of a subsequent VTE.

In the same set of models, six of eight surgical adverse events studied were found to be associated with higher risk of subsequent VTE $(\mathrm{p}<0.001$ for each significant association). Meanwhile, 8 of 13 medical adverse events were associated with increased risk of an ensuing VTE ( $p \leq 0.001$ for each significant comparison). The ORs for this set of regression analyses can be found in table 7 .

\section{DISCUSSION}

Among hospitalized children, VTE is an adverse event which is highly morbid and potentially preventable. Previous work has investigated VTE in hospitalized children, as well as in children after trauma. However, few studies have examined VTE in pediatric patients undergoing surgery for other indications. Consequently, at present, children-including those at high risk for VTE-do not routinely receive prophylactic anticoagulation after non-trauma-related surgery.

To better identify which pediatric surgical patients are at risk of VTE and may benefit from pharmacological

Table 4 Continuous perioperative variables in patients with and without postoperative VTE

\begin{tabular}{|c|c|c|c|c|}
\hline & Total & No VTE & VTE & \\
\hline & $n=361384$ & $n=361006(99.90 \%)$ & $n=378(0.10 \%)$ & \\
\hline Operative variable & Mean \pm SD & Mean \pm SD & Mean \pm SD & P value ${ }^{\star}$ \\
\hline Operative time, $\min$ & $95.57 \pm 93.27$ & $95.50 \pm 93.20$ & $163.52 \pm 129.07$ & $<0.001$ \\
\hline Length of stay, days & $4.61 \pm 13.53$ & $4.58 \pm 13.48$ & $30.92 \pm 29.04$ & $<0.001$ \\
\hline
\end{tabular}

${ }^{*}$ Two-tailed t-test comparing patients with and without VTE, assuming unequal variances following the result of Levene's test. Bolding indicates significance at $\mathrm{p}<0.025$ (Bonferroni correction for multiple comparisons).

$\mathrm{SD}$, standard deviation; VTE, venous thromboembolism. 
Table 5 Total incidences of postoperative adverse events, adverse events occurring before a VTE

\begin{tabular}{|c|c|c|c|c|}
\hline \multirow[b]{3}{*}{ Adverse event } & \multicolumn{2}{|l|}{ Total } & \multirow{2}{*}{\multicolumn{2}{|c|}{$\begin{array}{l}\text { Before VTE } \\
n=221(58.47 \% \text { of } \\
378 \text { VTE) }\end{array}$}} \\
\hline & \multicolumn{2}{|c|}{$n=361384$} & & \\
\hline & $\mathbf{n}$ & $\%$ & $\mathbf{n}$ & $\%$ of VTE \\
\hline Any adverse event & $48935^{\star}$ & 13.54 & 221 & 58.47 \\
\hline $\begin{array}{l}\text { Surgical adverse } \\
\text { event }\end{array}$ & 29284 & 8.10 & 139 & 36.77 \\
\hline Superficial SSI & 3536 & 0.98 & 6 & 1.59 \\
\hline Deep SSI & 766 & 0.21 & 4 & 1.06 \\
\hline Organ/Space SSI & 2766 & 0.77 & 19 & 5.03 \\
\hline $\begin{array}{l}\text { Superficial wound } \\
\text { dehiscence }\end{array}$ & 3514 & 0.97 & 8 & 2.12 \\
\hline $\begin{array}{l}\text { Deep wound } \\
\text { dehiscence }\end{array}$ & 1250 & 0.35 & - & 0.00 \\
\hline $\begin{array}{l}\text { Bleeding requiring } \\
\text { transfusion }\end{array}$ & 19454 & 5.38 & 117 & 30.95 \\
\hline Nerve injury & 154 & 0.04 & - & 0.00 \\
\hline Flap failure & 70 & 0.02 & 2 & 0.53 \\
\hline $\begin{array}{l}\text { Medical adverse } \\
\text { event }\end{array}$ & $8,277^{\star}$ & 2.29 & 93 & 24.60 \\
\hline Reintubation & 1789 & 0.50 & 40 & 10.58 \\
\hline Pneumonia & 1309 & 0.36 & 20 & 5.29 \\
\hline Sepsis & 1680 & 0.46 & 25 & 6.61 \\
\hline Septic shock & 299 & 0.08 & 12 & 3.17 \\
\hline CLABSI & 271 & 0.07 & 9 & 2.38 \\
\hline $\begin{array}{l}\text { Clostridium difficile } \\
\text { colitis }\end{array}$ & 281 & 0.08 & - & 0.00 \\
\hline UTI & 1812 & 0.50 & 10 & 2.65 \\
\hline Renal failure & 102 & 0.03 & 2 & 0.53 \\
\hline Renal insufficiency & 143 & 0.04 & 1 & 0.26 \\
\hline Stroke & 201 & 0.06 & - & 0.00 \\
\hline Seizure & 584 & 0.16 & 11 & 2.91 \\
\hline Cardiac arrest & 460 & 0.13 & 2 & 0.53 \\
\hline Coma & 21 & 0.01 & - & 0.00 \\
\hline Death & 1195 & 0.33 & N/A & \\
\hline Reoperation & 9812 & 2.72 & 57 & 15.08 \\
\hline Readmission & 17835 & 4.94 & 48 & 12.70 \\
\hline
\end{tabular}

*Any adverse event and medical adverse events include all cases of VTE.

CLABSI, central line-associated bloodstream infection; N/A, not applicable; SSI, surgical site infection; UTI, urinary tract infection; VTE, venous thromboembolism.

thromboprophylaxis, using a national surgical database of over 360000 children, the present study sought to characterize the incidence of VTE, and its risk factors, in children undergoing surgery across multiple surgical disciplines.

In a sample of 361384 patients from the NSQIP-P database (2012-2016), the present study finds an incidence of VTE of $0.10 \%$. This rate is consistent with previous
Table 6 Multivariable ORs for VTE, controlling for demographic and operative variables

\begin{tabular}{|c|c|c|c|}
\hline Variables & OR & $95 \% \mathrm{Cl}$ & P value ${ }^{\star}$ \\
\hline \multicolumn{4}{|l|}{ Age, years } \\
\hline$\leq 1$ & 0.992 & 0.715 to 1.376 & 0.961 \\
\hline $2-5$ & 1.074 & 0.761 to 1.516 & 0.683 \\
\hline $6-10$ & 0.625 & 0.414 to 0.940 & 0.024 \\
\hline $11-15$ & Referent & & \\
\hline $16-18$ & 1.892 & 1.374 to 2.606 & $<0.001$ \\
\hline \multicolumn{4}{|l|}{ Sex } \\
\hline Female & Referent & & \\
\hline Male & 0.977 & 0.797 to 1.199 & 0.827 \\
\hline \multicolumn{4}{|l|}{ ASA class } \\
\hline I & Referent & & \\
\hline II & 4.502 & 2.317 to 8.745 & $<0.001$ \\
\hline III & 19.715 & 10.316 to 37.677 & $<0.001$ \\
\hline IV & 71.17 & 36.339 to 139.386 & $<0.001$ \\
\hline V & 154.953 & 62.838 to 382.097 & $<0.001$ \\
\hline \multicolumn{4}{|l|}{ Surgical specialty } \\
\hline $\begin{array}{l}\text { Cardiothoracic } \\
\text { surgery }\end{array}$ & 3.248 & 1.293 to 8.156 & 0.012 \\
\hline Gynecology & 1.992 & 0.484 to 8.197 & 0.34 \\
\hline General surgery & Referent & & \\
\hline Neurosurgery & 0.622 & 0.463 to 0.837 & 0.002 \\
\hline $\begin{array}{l}\text { Orthopedic } \\
\text { surgery }\end{array}$ & 0.496 & 0.341 to 0.704 & $<0.001$ \\
\hline $\begin{array}{l}\text { Otolaryngology } \\
\text { (ENT) }\end{array}$ & 0.465 & 0.288 to 0.749 & 0.002 \\
\hline Urology & 0.31 & 0.162 to 0.594 & $<0.001$ \\
\hline Plastic surgery & 0.141 & 0.045 to 0.443 & 0.001 \\
\hline $\begin{array}{l}\text { Non-elective } \\
\text { surgery }\end{array}$ & 1.678 & 1.332 to 2.114 & $<0.001$ \\
\hline $\begin{array}{l}\text { Operative time } \\
\text { (min) }\end{array}$ & 1.004 & 1.003 to 1.004 & $<0.001$ \\
\hline
\end{tabular}

*Logistic regression including all variables listed in this table. Bolding indicates statistical significance at $p<0.05$.

ASA, American Society of Anesthesiologists; Cl, confidence interval; ENT, ear, nose and throat; OR, odds ratio; VTE, venous thromboembolism.

reports of VTE in children, which find incidences of VTE of between $0.0629 \%^{1}$ and $0.10 \%^{28}$ in orthopedic surgery, $0.038 \%$ in general surgery ${ }^{14}$ and $0.12 \%^{29}$ to $8.9 \%^{30}$ in trauma. ${ }^{6} 183132$

Regarding risk factors for VTE, controlling for demographic and surgical variables, compared with patients aged 11-15 years, the present study identifies significantly increased risk of VTE among patients aged 16-18 years $(\mathrm{OR}=1.892, \mathrm{p}<0.001)$, with children aged $6-10$ years at lower risk $(\mathrm{OR}=0.625, \mathrm{p}=0.024)$. This finding is consistent with previous studies, which suggests that adolescents are at higher risk for VTE. ${ }^{1017183133}$ As an example, a study of 
Table 7 Multivariable ORs for VTE, considering adverse events that occurred before a VTE

\begin{tabular}{|c|c|c|c|}
\hline Adverse event & OR & $95 \% \mathrm{Cl}$ & P value* \\
\hline Any adverse event & 13.275 & 10.490 to 16.060 & $<0.001$ \\
\hline Surgical adverse event & 12.358 & 9.559 to 15.156 & $<0.001$ \\
\hline Superficial SSI & 9.134 & 6.115 to 12.152 & $<0.001$ \\
\hline Deep SSI & 8.179 & 5.032 to 11.325 & $<0.001$ \\
\hline Organ/Space SSI & 10.746 & 7.809 to 13.683 & $<0.001$ \\
\hline Superficial wound dehiscence & 9.132 & 6.129 to 12.136 & $<0.001$ \\
\hline Deep wound dehiscence & $\dagger$ & & \\
\hline Bleeding requiring transfusion & 12.009 & 9.207 to 14.810 & $<0.001$ \\
\hline Flap failure & 6.448 & 3.386 to 9.511 & $<0.001$ \\
\hline Nerve injury & $\dagger$ & & \\
\hline Medical adverse event & 11.750 & 8.957 to 14.543 & $<0.001$ \\
\hline Reintubation & 10.597 & 7.773 to 13.420 & $<0.001$ \\
\hline Pneumonia & 9.931 & 7.053 to 12.809 & $<0.001$ \\
\hline Sepsis & 10.244 & 7.421 to 13.068 & $<0.001$ \\
\hline Septic shock & 9.152 & 6.292 to 12.012 & $<0.001$ \\
\hline CLABSI & 9.328 & 6.323 to 12.333 & $<0.001$ \\
\hline Clostridium difficile colitis & $\dagger$ & & \\
\hline UTI & 9.616 & 6.709 to 12.524 & $<0.001$ \\
\hline Renal failure & 7.172 & 3.947 to 10.396 & $<0.001$ \\
\hline Renal insufficiency & 5.405 & 2.120 to 8.690 & 0.001 \\
\hline Stroke & $\dagger$ & & \\
\hline Seizure & $\dagger$ & & \\
\hline Cardiac arrest & $\dagger$ & & \\
\hline Coma & $\dagger$ & & \\
\hline Reoperation & 11.479 & 8.668 to 14.290 & $<0.001$ \\
\hline Readmission & 11.741 & 8.931 to 14.551 & $<0.001$ \\
\hline
\end{tabular}

${ }^{*}$ Firth logistic regressions to determine the OR of VTE for preceding adverse events. Each regression controls variables of patient age, sex and ASA class. Bolding indicates statistical significance at $p<0.05$.

†Insufficient number of observations for regression analysis.

ASA, American Society of Anesthesiologists; Cl

, confidence interval; CLABSI, central line-associated bloodstream infection; OR, odds ratio; SSI, surgical site infection; UTI, urinary tract infection; VTE, venous thromboembolism.

hospitalized pediatric patients finds that compared with patients aged 1-4 years, those aged 15-17 years are at more than twice the risk of VTE. ${ }^{7}$ Similarly, the APAGBI guidelines identify patients older than 13 years as being at higher risk for VTE. ${ }^{24}$

When separated from children aged 2-5 years, children aged 1 year or younger were not found to be at significantly increased risk for VTE, a finding that differs somewhat from previous studies, which have suggested that neonates are at increased risk for VTE. ${ }^{19}$ The results of the present study could differ from those of prior analyses because of differences in the procedures and populations studied.

Regarding comorbidities, controlling for other factors, worse health status-as indicated by an ASA class $>$ I-was significantly associated with VTE (compared with ASAclass I, ASA class II OR=4.502, ASA class III OR=19.715, ASA class IV OR=71.170, ASA class V OR=154.953; $\mathrm{p}<0.001$ for all). Consistent with this finding, compared with patients who did not develop a postoperative VTE, patients with VTE had a significantly higher incidence of all seven types of comorbidities studied. Considered together, the finding that higher ASA class is associated with a higher risk of VTE, and the observation that multiple comorbidities are more common among patients with VTE, suggests that pediatrics patients who are sicker are predisposed to postoperative VTE, with no single comorbidity driving this association. These findings aligned with previous work, which found that pediatric patients who developed VTE after surgery had at least one comorbid condition. ${ }^{5}$ This is also consistent with the finding that, among adult patients, those with a higher comorbidity burden are at higher risk for VTE. ${ }^{34-36}$ 
Surgical specialty was another factor independently associated with patients' risk of VTE. Controlling for demographic and other operative factors, compared with general surgery (the specialty that treated the greatest number of patients in the study population), the present study found several surgical specialties to be independently associated with lower risk of VTE, including orthopedic surgery and plastic surgery $(\mathrm{OR}=0.496, \mathrm{p}<0.001$ and $\mathrm{OR}=0.141, \mathrm{p}=0.001$, respectively). The result of plastic surgery was consistent with adult literature. ${ }^{37}$ However, the result with orthopedic surgery was not expected and had not previously been reported.

Furthermore, neurosurgery, otolaryngology and urology were also found to have lower odds of VTE compared with general surgery. It is possible that this reflects a higher risk of VTE in the general surgical population rather than a reduction in risk conferred by other surgical specialties.

Patients undergoing cardiothoracic surgery, however, were found to be at higher risk of VTE when compared with patients receiving general surgery. This is consistent with previous literature in pediatric surgery, which finds higher rates of VTE after cardiothoracic procedures. ${ }^{38}$

Longer operative time was independently associated with VTE, while patients with VTE also had longer hospitalizations. An association between hospital length of stay and VTE risk in children had been reported previously, ${ }^{7729}$ as with operative time. ${ }^{1213} 38$ These findings are further corroborated in the literature around VTE in adults, where studies have found that longer operative times ${ }^{39}$ and longer hospital stays ${ }^{39}$ are associated with VTE.

Further relating to surgery, non-elective surgery was significantly associated with VTE. This finding is consistent with a study by Baker et al, which demonstrates a higher incidence of VTE in emergent surgery among pediatric patients undergoing orthopedic surgery. ${ }^{28}$ These findings are consistent with the adult literature, which identifies non-elective surgery as a risk factor for thromboembolic events. ${ }^{40}$

Two recent studies have reported similar overall analyses. Ahn et al similarly used NSQIP-P to evaluate preoperative and perioperative factors associated with VTE in children undergoing surgery. ${ }^{13}$ On multivariate analysis, the authors identify several risk factors for VTE: female sex, longer prehospital stay prior to surgery, current malignancy, preoperative mechanical ventilation, developmental delay, preoperative blood transfusion, preoperative infection and anesthesia time $>2$ hours. Additionally, age of 2-9 years and Hispanic ethnicity were found to be negatively associated with VTE. The only variable associated with VTE consistently identified on multivariate analysis between the present study and that by Ahn et al is longer operative time, although all types of comorbidities examined in the current study are more common among patients with VTE. There are two reasons that potentially account for these differences. They focused on comorbidities individually as opposed to grouped as ASA, and did not account for postoperative adverse events.

Similarly, Cairo et al identify risk factors for VTE in children undergoing abdominopelvic surgery. ${ }^{12}$ In multivariate analysis, the authors found associations between VTE and age $>15$ years, longer anesthesia time, preoperative renal failure, preoperative septic shock and ASA class $>$ I. The present analysis similarly finds older age, longer operative time and ASA class $>\mathrm{I}$ to be associated with VTE.

Distinguishing the current study from these prior studies, to the authors' knowledge, the present study is the only study to date to consider postoperative adverse events and their relationship to VTE. Neither the studies by Ahn et al nor Cairo et al perform similar analyses.

In addition to identifying demographics, comorbidities and operative factors associated with postoperative VTE, the present study sought to identify postoperative adverse events that predisposed patients to VTE. In logistic regression analyses controlling for demographics and operative variables, a majority of adverse events studied were associated with VTE. Of the eight surgical adverse events examined, six were significantly associated with a subsequent VTE: SSI (superficial, deep and organ/space), superficial wound dehiscence, bleeding requiring transfusion, and flap failure. Additionally, medical adverse events were associated with a higher risk of VTE. Furthermore, reoperation was significantly associated with a subsequent VTE. In the adult literature, postoperative pneumonia has been found to be associated with VTE. ${ }^{41}$ While not discernible from the dataset, it is likely that patients who sustain adverse events are less mobile after their complications, with stasis predisposing these patients to VTE.

Overall, the current study identified demographic, surgical and postoperative variables associated with the occurrence of VTE in children. Taken together, these findings suggest that children who are older, sicker (higher ASA class and comorbidity burden), who have longer, non-elective surgeries and who undergo general surgery or cardiothoracic surgery, are at higher risk of developing VTE. Furthermore, patients who develop any adverse event postoperatively, be it a surgical or medical complication, are at increased risk of an ensuing VTE.

The present study has several limitations. Foremost, the study faces the constraints of all retrospective analyses: namely, its limited ability to establish causal relationships between factors observed. Second, because NSQIP includes only the postoperative day on which an adverse event occurs, rather than the time, adverse events around a VTE can only be identified if they occur on different postoperative days from the VTE. This limitation somewhat blunted the study's ability to establish temporal relationships between adverse events. Third, the database does not include equal numbers of surgeries across surgical disciplines. Fourth, patients were only followed for 30 postoperative days. Therefore, adverse events occurring outside of this period were not captured. Fifth, 
the present analysis is unable to identify which patients, if any, received chemoprophylaxis, or received postoperative anticoagulation. Sixth, there is not a universal screening protocol in place for VTE across the hospitals across the dataset. Therefore, interhospital variability in detection of VTE could affect the rate at which VTE was identified, likely leading to under-reporting.

With the above said, the current study clearly shows that certain pediatric subpopulations undergoing surgery are at elevated risks for VTE than the baseline postoperative VTE risk of $0.10 \%$. The current study identified patient and surgery-related risk factors for postoperative VTE in children: older age, higher ASA class, non-elective surgery, general surgery and cardiothoracic surgery and longer operative time. Postoperatively, the study found that any adverse event, including medical and surgical adverse events, reoperation and readmission were associated with higher odds of an ensuing VTE.

Considering an illustrative example, according to the results of the current study, patients with ASA class III with at least one comorbidity who undergo non-elective surgery and experience a surgical postoperative adverse event would have a 19-fold higher incidence of VTE (overall incidence of $1.92 \%$ ). These findings should clearly come into considerations when weighing the risks and benefits of VTE prophylaxis in pediatric postoperative patients.

Contributors RPM and EJM contributed to study design, data analysis, manuscript preparation and review. JNG contributed to study design, manuscript preparation and review.

Funding The authors have not declared a specific grant for this research from any funding agency in the public, commercial or not-for-profit sectors.

Competing interests JNG has received payments from Bioventus, TIDI Products, Medtronic and Stryker. He is also a Fellow of the American College of Surgeons All other authors certify that they have no commercial associations (eg, consultancies, stock ownership, equity interest, patent/licensing arrangements, etc) that might pose a conflict of interest in connection with the submitted article.

Patient consent for publication Not required.

Ethics approval The current study was found to be exempt from Institutional Review Board review.

Provenance and peer review Not commissioned; externally peer reviewed.

Data availability statement Data used in the study are available through the American College of Surgeons' National Surgical Quality Improvement Project.

Open access This is an open access article distributed in accordance with the Creative Commons Attribution Non Commercial (CC BY-NC 4.0) license, which permits others to distribute, remix, adapt, build upon this work non-commercially, and license their derivative works on different terms, provided the original work is properly cited, appropriate credit is given, any changes made indicated, and the use is non-commercial. See: http://creativecommons.org/licenses/by-nc/4.0/.

ORCID iD

Jonathan Newman Grauer http://orcid.org/0000-0002-2626-7278

\section{REFERENCES}

1 Georgopoulos G, Hotchkiss MS, McNair B, et al. Incidence of deep vein thrombosis and pulmonary embolism in the elective pediatric orthopaedic patient. Journal of Pediatric Orthopaedics 2016;36:101-9.

2 Andrew M, David M, Adams M, et al. Venous thromboembolic complications (VTe) in children: first analyses of the Canadian registry of VTe. Blood 1994;83:1251-7.
3 Jung HL. Venous thromboembolism in children and adolescents. Blood Res 2016;51:3.

4 Kerlin BA. Current and future management of pediatric venous thromboembolism. Am J Hematol 2012;87 Suppl 1:S68-74.

5 Raffini L, Huang Y-S, Witmer C, et al. Dramatic increase in venous thromboembolism in children's hospitals in the United States from 2001 to 2007. Pediatrics 2009;124:1001-8.

6 Sandoval JA, Sheehan MP, Stonerock CE, et al. Incidence, risk factors, and treatment patterns for deep venous thrombosis in hospitalized children: an increasing population at risk. J Vasc Surg 2008;47:837-43.

7 Vu LT, Nobuhara KK, Lee H, et al. Determination of risk factors for deep venous thrombosis in hospitalized children. $J$ Pediatr Surg 2008;43:5-1099.

8 Setty BA, O'Brien SH, Kerlin BA. Pediatric venous thromboembolism in the United States: a tertiary care complication of chronic diseases. Pediatr Blood Cancer 2012;59:258-64.

9 Takemoto CM, Sohi S, Desai K, et al. Hospital-Associated venous thromboembolism in children: incidence and clinical characteristics. J Pediatr 2014;164:332-8.

10 Thompson AJ, McSwain SD, Webb SA, et al. Venous thromboembolism prophylaxis in the pediatric trauma population. $J$ Pediatr Surg 2013;48:1413-21.

11 Cyr C, Michon B, Pettersen G, et al. Venous thromboembolism after severe injury in children. Acta Haematol 2006;115:198-200.

12 Cairo SB, Lautz TB, Schaefer BA, et al. Risk factors for venous thromboembolic events in pediatric surgical patients: defining indications for prophylaxis. J Pediatr Surg 2018;53:1996-2002.

13 Ahn JJ, Merguerian PA, Shnorhavorian M. Incidence and risk factors associated with 30-day post-operative venous thromboembolism: a NSQIP-pediatric analysis. J Pediatr Urol 2018;14:335.e1-335.e6.

14 Humes DJ, Nordenskjöld A, Walker AJ, et al. Risk of venous thromboembolism in children after general surgery. J Pediatr Surg 2015;50:1870-3.

15 Vavilala MS, Nathens AB, Jurkovich GJ, et al. Risk factors for venous thromboembolism in pediatric trauma. J Trauma 2002;52:922-7.

16 Candrilli SD, Balkrishnan R, O'Brien SH. Effect of injury severity on the incidence and utilization-related outcomes of venous thromboembolism in pediatric trauma inpatients. Pediatr Crit Care Med 2009;10:554-7.

17 Yen J, Arendonk K, Streiff M et al. Risk factors for venous thromboembolism in pediatric trauma patients and validation of a novel scoring system: the risk of clots in kids with trauma (ROCKIT score). Pediatric Critical Care Medicine 2016;17:9.

18 Van Arendonk KJ, Schneider EB, Haider AH, et al. Venous thromboembolism after trauma: when do children become adults? JAMA Surg 2013;148:1123-30.

19 O'Brien SH, Candrilli SD. In the absence of a central venous catheter, risk of venous thromboembolism is low in critically injured children, adolescents, and young adults: evidence from the National trauma data bank. Pediatr Crit Care Med 2011;12:251-6.

20 Walker AJ, Grainge MJ, Card TR, et al. Venous thromboembolism in children with cancer - a population-based cohort study. Thromb Res 2014:133:340-4.

21 Biss T. Venous thromboembolism in children: is it preventable? Semin Thromb Hemost 2016;42:603-11.

22 Goldenberg NA, Donadini MP, Kahn SR, et al. Post-Thrombotic syndrome in children: a systematic review of frequency of occurrence, validity of outcome measures, and prognostic factors. Haematologica 2010;95:1952-9.

23 Napolitano LM. Venous thromboembolism prevention in pediatric Trauma-Time for national guidelines. JAMA Surg 2013;148:1130-1.

24 Morgan J, Checketts M, Arana A, et al. Prevention of perioperative venous thromboembolism in pediatric patients: guidelines from the association of paediatric anaesthetists of great britain and ireland (APAGBI). Pediatr Anaesth 2018;28:382-91.

25 Chalmers E, Ganesen V, Liesner R, et al. Guideline on the investigation, management and prevention of venous thrombosis in children*. Br J Haematol 2011;154:196-207.

26 Hanson SJ, Punzalan RC, Arca MJ, et al. Effectiveness of clinical guidelines for deep vein thrombosis prophylaxis in reducing the incidence of venous thromboembolism in critically ill children after trauma. J Trauma Acute Care Surg 2012;72:1292-7.

27 King G, Zeng L. Logistic regression in rare events data. Political Analysis 2001;9:137-63.

28 Baker D, Sherrod B, McGwin G, et al. Complications and 30day outcomes associated with venous thromboembolism in the pediatric orthopaedic surgical population. J Am Acad Orthop Surg 2016;24:196-206.

29 Harris DA, Lam S. Venous thromboembolism in the setting of pediatric traumatic brain injury. J Neurosurg 2014;13:448-55 
30 Leeper CM, Vissa M, Cooper JD, et al. Venous thromboembolism in pediatric trauma patients: ten-year experience and long-term followup in a tertiary care center. Pediatr Blood Cancer 2017;64:e26415.

31 Connelly CR, Laird A, Barton JS, et al. A clinical tool for the prediction of venous thromboembolism in pediatric trauma patients. JAMA Surg 2016;151:8.

32 Allen CJ, Murray CR, Meizoso JP, et al. Risk factors for venous thromboembolism after pediatric trauma. J Pediatr Surg 2016;51:168-71.

33 Greenwald LJ, Yost MT, Sponseller PD, et al. The role of clinically significant venous thromboembolism and thromboprophylaxis in pediatric patients with pelvic or femoral fractures. J Pediatr Orthop 2012;32:357-61.

34 Trinh VQ, Karakiewicz PI, Sammon J, et al. Venous thromboembolism after major cancer surgery: temporal trends and patterns of care. JAMA Surg 2014;149:43-9.

35 Pedersen AB, Mehnert F, Sorensen HT, et al. The risk of venous thromboembolism, myocardial infarction, stroke, major bleeding and death in patients undergoing total hip and knee replacement: a 15 -year retrospective cohort study of routine clinical practice. Bone Joint J 2014;96-B:479-85.
36 Tashjian RZ, Lilly DT, Isaacson AM, et al. Incidence of and risk factors for symptomatic venous thromboembolism after shoulder arthroplasty. Am J Orthop 2016;45:E379-85.

37 Cramer JD, Dilger AE, Schneider A, et al. Risk of venous thromboembolism among otolaryngology patients vs general surgery and plastic surgery patients. JAMA Otolaryngol Head Neck Surg 2018;144:9-17.

38 Sherrod BA, McClugage SG, Mortellaro VE, et al. Venous thromboembolism following inpatient pediatric surgery: analysis of 153,220 patients. J Pediatr Surg 2019;54:631-9.

39 Ejaz A, Spolverato G, Kim Y, et al. Defining incidence and risk factors of venous thromboemolism after hepatectomy. $J$ Gastrointest Surg 2014;18:1116-24.

40 Nelson DW, Simianu VV, Bastawrous AL, et al. Thromboembolic complications and prophylaxis patterns in colorectal surgery. JAMA Surg 2015;150:712-20.

41 Kimmell KT, Walter KA. Risk factors for venous thromboembolism in patients undergoing craniotomy for neoplastic disease. $J$ Neurooncol 2014;120:567-73. 